\title{
First report of Toxoplasma gondii seroprevalence in wild-caught Caribbean African green monkeys
}

\author{
Clare M Hamilton ${ }^{1,2}$, Frank Katzer ${ }^{1}$, Amy Beierschmitt ${ }^{2,3}$, Esteban Soto ${ }^{2}$, Elisabeth A Innes ${ }^{1}$ and Patrick J Kelly ${ }^{2 *}$
}

\begin{abstract}
Background: Toxoplasma gondii is a protozoan parasite capable of infecting all warm-blooded animals. Humans can become infected by ingesting infective oocysts from the environment or contaminated food or water, or by ingesting tissue cysts in undercooked infected meat or by handling infected meat. Caribbean African green monkeys (Chlorocebus sabaeus) are present in large numbers on the island of St. Kitts in the Caribbean, and it is not uncommon for these animals to be trapped and eaten by islanders. The aim of this study was to determine T. gondii infection in Caribbean African green monkeys.
\end{abstract}

Findings: Sera collected from 79 wild-caught Caribbean African green monkeys were examined for T. gondii antibodies by ELISA. Antibodies were detected in 38 out of 79 (48.1\%) monkeys. Significantly more females were infected than males but there was no significant effect of age or location on antibody status.

Conclusions: Results indicate that Caribbean African green monkeys can be infected with $T$. gondii and that there is widespread environmental contamination of St. Kitts with oocysts. These monkeys could present a potential source of T. gondii infection if their meat is consumed undercooked. This is the first report of $T$. gondii antibodies in this species.

Keywords: Toxoplasma gondii, Vervet monkey, Chlorocebus sabaeus, Seroprevalence, St. Kitts

\section{Findings \\ Background}

Toxoplasma gondii is a ubiquitous protozoan parasite capable of infecting all warm-blooded animals [1]. In intermediate hosts, such as humans and non-human primates, the parasite develops into a cystic form in the tissues which may persist in a viable state for the lifetime of the host. Humans become infected with $T$. gondii by ingesting tissue cysts from raw or undercooked meat, or by ingesting oocysts (shed in infected cat faeces) from contaminated food or water or directly from the environment.

Toxoplasmosis has a wide spectrum of clinical responses following infection which ranges from acute fatal disease, congenital disease, behavioural changes and no obvious clinical signs [2]. The outcome of $T$. gondii infection may be influenced by factors such as the definitive host, whether or not the host species has evolved alongside the cat, how the immune system responds to the infection, and the influence of the parasite strain. Most T. gondii

\footnotetext{
* Correspondence: pkelly@rossvet.edu.kn

${ }^{2}$ Ross University School of Veterinary Medicine, PO Box 334, Basseterre, St. Kitts, West Indies

Full list of author information is available at the end of the article
}

infections are mild or asymptomatic but the differing pathogenicity of the parasite is evident in lemurs [3], Australian marsupials [4] and new world monkeys [5] where the parasite is highly virulent and can cause severe clinical symptoms and even death in a primary infection. Unlike new world monkeys, old world monkeys, such as the African green monkeys (Chlorocebus sabaeus), are less susceptible to clinical disease and there are few reports of toxoplasmosis in these hosts.

St. Kitts is a small island located in the Eastern Caribbean with a population of approximately 35,000 people. African green monkeys (AGM) were introduced to the island in the 1700s when they were transported across the Atlantic from West Africa during the slave trade. Many slavers brought them as pets or to be sold or traded for goods [6]. Today, there are populations of Caribbean AGM on St. Kitts, Nevis and Barbados. On St. Kitts, the population of Caribbean AGM is estimated at 55,000 which significantly outnumbers the human population. Their large numbers can be problematic, with habitat and crop destruction impacting on the livelihoods of local residents. They are considered a pest and it is not uncommon for the monkeys to be 
trapped and killed, and their meat consumed as bush meat [7].

Previous work on St. Kitts demonstrated a high T. gondii seroprevalence in cats [8,9] and small ruminants [10], suggesting widespread environmental contamination with oocysts. Although we could find no report of T. gondii infection in AGM, these animals occur throughout St. Kitts and may be sentinels for environmental contamination. To provide further data on the distribution of T. gondii on St. Kitts, we examined sera from wild monkeys trapped around the island and report our results below.

\section{Methods}

Seventy nine Caribbean AGM (Chlorocebus sabaeus) were trapped at 7 different locations throughout St. Kitts (Figure 1) and brought to a quarantine site which directly serves the Behavioural Science Foundation, St. Kitts [11]. Animals were anesthetized and $2 \mathrm{ml}$ of whole blood was collected from the femoral vein as part of a larger study which received ethical approval from the Institutional Animal Care and Use Committee (IACUC), Ross University School of Veterinary Medicine, St. Kitts [11]. Further ethical approval for screening the sera for $T$. gondii antibodies was granted by IACUC. Sera were separated and stored at $-80^{\circ} \mathrm{C}$.

All sera were examined for $T$. gondii antibodies using an in-house ELISA which has been reported to have a sensitivity of $99 \%$ and a specificity of $99.4 \%$ [12], with modifications. In brief, 96-well microtitre plates were coated overnight with $6 \mu \mathrm{g} / \mathrm{ml}$ solubilised RH antigen [13], washed with PBST
(PBS with $0.05 \%$ Tween-20) and incubated for $1 \mathrm{hr}$ at room temperature (approximately $25^{\circ} \mathrm{C}$ ) after addition of $100 \mu \mathrm{l}$ test or control sera (diluted 1:100 in 1\% BSA in PBST) per well. Following washing, $100 \mu \mathrm{l} \mathrm{HRP-conjugated} \mathrm{Protein} \mathrm{G}$ (Life Technologies Ltd, UK), diluted 1:10,000 in PBST with $1 \%$ BSA, was added to each well and plates incubated for $1 \mathrm{~h}$ at room temperature. ELISAs were developed with TMB and reactions stopped with $2 \mathrm{M} \mathrm{H}_{2} \mathrm{SO}_{4}$ before ODs were read at $450 \mathrm{~nm}$. Control sera were pooled samples of 5 positive and 5 negative human serum samples from a previous study (Burrells et al. unpublished observations). For each plate, the cut-off value was calculated as two times the percent positivity of the negative control serum relative to the positive control serum (i.e. $2 \times$ (average negative control sera $\mathrm{OD} /$ average positive control sera OD) $\times 100$ ) [14]

Effects of gender, age and location on T. gondii antibody status were investigated using a general linear model. A $P$ value of $<0.05$ was deemed significant.

\section{Results}

Antibodies to T. gondii were detected in 38 out of 79 (48.1\%; 95\% confidence interval (CI): 37.4-59.0\%) Caribbean African green monkeys (Figure 2). Of the 77 monkeys which had their gender recorded, 33 were male and 44 were female. Of the 38 Toxoplasma-positive monkeys, 28 (73.7\%; CI: 58.0-85.0\%) were female and 10 (26.3\%; CI: 15.0-42.0\%) were male (Figure 2). Females were significantly more likely to be seropositive than males $(P=0.04)$. Monkeys were caught from 7 locations across the island,

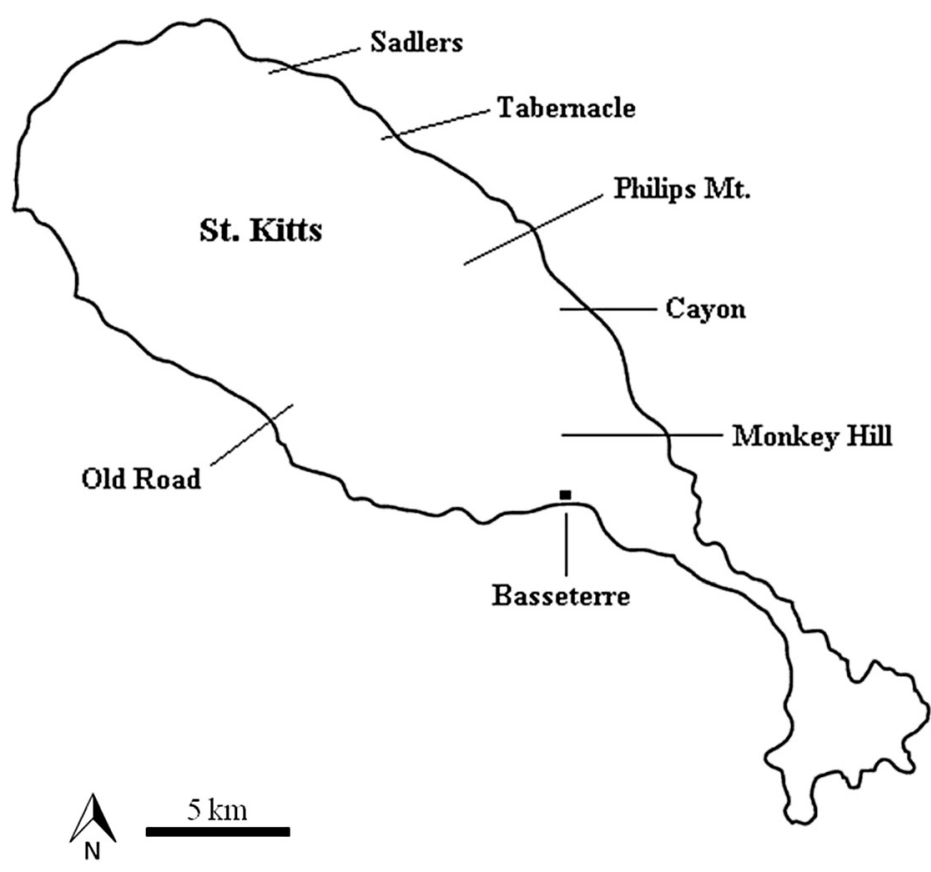

Nevis

Figure 1 Map of St. Kitts depicting the trapping sites of the wild-caught monkeys and the island capital, Basseterre. 


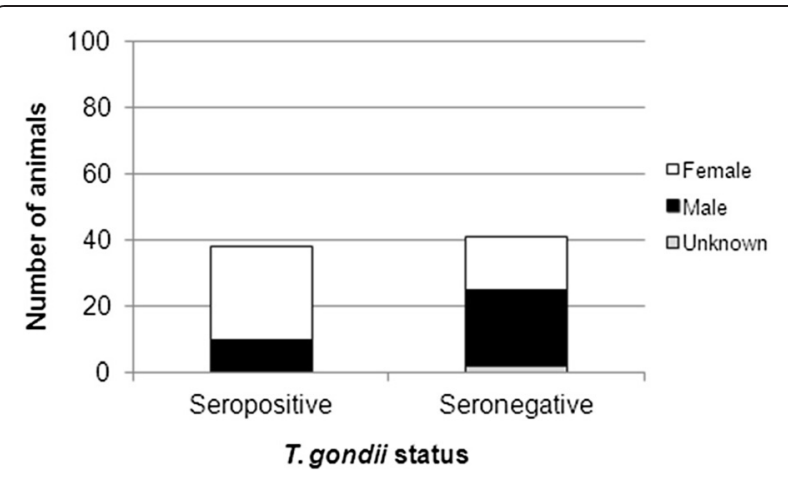

Figure 2 Number of $T$. gondii seropositive and seronegative monkeys.

and each site had at least one positive monkey (Table 1). There was no significant affect of age or location on T. gondii antibody status.

\section{Discussion}

This is the first study to show evidence of $T$. gondii infections in green monkeys. Green monkeys are opportunistic omnivores but in St. Kitts a large component of their diet consists of wild fruits, flowers and leaves. The high seroprevalence reported in the present study suggests a high level of environmental contamination with oocysts shed in infected cat faeces. Previous studies on St. Kitts have demonstrated a very high seroprevalence of $T$. gondii in both domestic and feral cat populations $[8,9]$, suggesting that there could be wide spread contamination with oocysts. Following a primary infection, cats may shed up to 55 million oocysts per day into the environment [15]. In the warm temperatures of St. Kitts, these oocysts may sporulate and become infective in less than 1 day if there is also sufficient humidity and aeration [16]. Sporulated oocysts of T. gondii are very resistant to environmental conditions and can remain infective

Table 1 Geographical distribution of $T$. gondii-positive monkeys in St. Kitts

\begin{tabular}{llll}
\hline Island location & n tested & n positive & \% positive $(\mathbf{C l})$ \\
\hline Cayon & 8 & 4 & $50.0(21.5-78.5 \%)$ \\
Monkey Hill & 3 & 1 & $33.3(6.2-79.2 \%)$ \\
Old Road & 30 & 14 & $46.7(30.2-63.9 \%)$ \\
Phillips Mt. & 9 & 4 & $44.4(18.9-73.3 \%)$ \\
Saddlers Mt. & 19 & 9 & $47.4(27.3-68.3 \%)$ \\
Saddlers & 3 & 3 & $100.0(43.9-100.0 \%)$ \\
Tabernacle & 6 & 2 & $33.3(9.7-70.0 \%)$ \\
Unknown & 1 & 1 & $100.0(20.7-100.0 \%)$ \\
TOTAL & 79 & 38 & \\
\hline
\end{tabular}

in moist soil or sand for up to 18 months [17]. Although previous studies on cats in St. Kitts focused on one area of the island (Basseterre), local experience shows feral and free-roaming cats are present all over the island and may contribute to dissemination of $T$. gondii oocysts in the environment thus presenting a potential route of transmission to the monkeys. This was reflected in the finding that at least one monkey from each island location was seropositive for T. gondii.

Green monkeys also consume insects and earthworms in their diet, which could increase their chance of ingesting any oocysts that may be present in the soil. It is possible that the monkeys may also have been infected congenitally, as this route of transmission has been reported in non-human primates. Experimental infection of rhesus macaques (Macaca mulatta) with $T$. gondii resulted in abortion as well as congenital and ocular toxoplasmosis $[18,19]$. The youngest monkey in the present study was 3 years old, so it is not possible to surmise whether congenital infection is a significant transmission route in these animals.

In this study, although the sample size was small, seroprevalence was significantly higher in female monkeys than in male monkeys. The average estimated age of the female monkeys was 5.7 years, and 6.8 years for the male monkeys, so it is unlikely that age played a role in the differing seroprevalence rates. Indeed, there was no significant effect of age on antibody status of the monkeys. Higher T. gondii seroprevalence in females has been reported for other animals, including donkeys [20] and pigs [21]; however, gender is not thought to be a significant risk factor for T. gondii infection.

It is well documented that new world monkeys, such as the squirrel monkey (Saimiri sciureus), are more susceptible to toxoplasmosis than old world monkeys and can suffer fatal multisystemic disease [5,22]. There are few reports of $T$. gondii in old world monkeys [23-25] and none reports clinical signs of toxoplasmosis. To our knowledge, our study is the first to indicate that Caribbean AGM can be infected with $T$. gondii.

With an estimated population of 55,000, the Caribbean AGM on St. Kitts are a significant pest to farmers and islanders growing their own fruit and vegetables [7]. Consequently, the monkeys are not uncommonly killed and sometimes eaten as bush meat [7]. Our finding of seropositive monkeys suggests they could be a source of T. gondii if they harbour viable tissue cysts and their meat is consumed raw or undercooked. Consumption of undercooked infected meat has been identified as a significant risk factor in several case-control studies on Toxoplasma infection in humans [26]. To prevent foodborne transmission, meat should be thoroughly cooked $\left(67^{\circ} \mathrm{C}\right.$ or higher) before consumption [27] and it should not be tasted during preparation or cooking [26]. 


\section{Conclusions}

In conclusion, this is the first report of $T$. gondii antibodies in Caribbean AGM and the high exposure rates we found on St. Kitts indicate widespread environmental contamination of the island with oocysts. Further studies are in planning to determine the role bush meat might play in the epidemiology of the organism on St. Kitts.

\section{Competing interests}

The authors declare that they have no competing interests.

\section{Authors' contributions}

$\mathrm{CMH}$ performed all serological screening and data analysis, and drafted the manuscript. FK and EAI provided antigenic material and control sera for the ELISAs, and revised the manuscript. AB and ES conducted the original study which generated the serum samples used in the present study, and also revised the manuscript. PJK participated in the design of the study, sought ethical approval for additional serum samples to be taken, and also revised the manuscript. All authors read and approved the final manuscript.

\section{Acknowledgements}

The authors would like to thank Professor Stephen Rushton, Newcastle University, UK, for performing the statistical analysis. We also thank Dr. Roberta Palmour, Behavioural Science Foundation, St. Kitts, for comments on the manuscript. This work was funded by Ross University School of Veterinary Medicine and the Moredun Research Institute.

\section{Author details}

'Moredun Research Institute, Pentlands Science Park, Bush Loan, Edinburgh EH26 OPZ, UK. ${ }^{2}$ Ross University School of Veterinary Medicine, PO Box 334, Basseterre, St. Kitts, West Indies. 'B Behavioural Science Foundation, PO Box 428, Estridge Estate, Basseterre, St. Kitts, West Indies.

Received: 30 July 2014 Accepted: 25 November 2014

Published online: 10 December 2014

\section{References}

1. Dubey JP: The history of Toxoplasma gondii-the first 100 years. J Eukaryot Microbiol 2008, 55:467-475.

2. Innes EA: A brief history and overview of Toxoplasma gondii. Zoonoses Public Health 2010, 57:1-7.

3. Juan-Salles C, Mainez M, Marco A, Sanchis AM: Localized toxoplasmosis in a ring-tailed lemur (Lemur catta) causing placentitis, stillbirths, and disseminated fetal infection. J Vet Diagn Invest 2011, 23:1041-1045.

4. Fernandez-Aguilar X, Ajzenberg D, Cabezon O, Martinez-Lopez A, Darwich L, Dubey JP, Almeria S: Fatal toxoplasmosis associated with an atypical Toxoplasma gondii strain in a Bennett's wallaby (Macropus rufogriseus) in Spain. Vet Parasitol 2013, 196:523-527.

5. Epiphanio S, Sinhorini IL, Catao-Dias JL: Pathology of toxoplasmosis in captive new world primates. J Comp Pathol 2003, 129:196-204.

6. van der Kuyl AC, Dekker JT, Goudsmit J: St. Kitts green monkeys originate from West Africa: genetic evidence from feces. Am J Primatol 1996, 40:361-364.

7. Sade DS, Hildrech RW: Notes on the Green Monkey (Cercopithecus aethiops sabeus) on St. Kitts, West Indies. Carib J Sci 1965, 5:67-82.

8. Moura L, Kelly P, Krecek RC, Dubey JP: Seroprevalence of Toxoplasma gondii in cats from St. Kitts, West Indies. J Parasitol 2007, 93:952-953.

9. Dubey JP, Moura L, Majumdar D, Sundar N, Velmurugan GV, Kwok OC, Kelly P, Krecek RC, Su C: Isolation and characterization of viable Toxoplasma gondii isolates revealed possible high frequency of mixed infection in feral cats (Felis domesticus) from St Kitts, West Indies. Parasitology 2009, 136:589-594.

10. Hamilton CM, Katzer F, Innes EA, Kelly PJ: Seroprevalence of Toxoplasma gondii in small ruminants from four Caribbean islands. Parasit Vectors 2014, 7:449-452.

11. Whitehouse CA, Keirstead N, Taylor J, Reinhardt JL, Beierschmitt A: Prevalence of hypermucoid Klebsiella pneumoniae among wild-caught and captive vervet monkeys (Chlorocebus aethiops sabaeus) on the island of St. Kitts. J Wildl Dis 2010, 46:971-976.
12. Burrells A: Toxoplasma gondii in animal and human hosts. Ph.D Thesis. University of Edinburgh; 2014.

13. Hughes HP, Van Knapen F, Atkinson HJ, Balfour AH, Lee DL: A new soluble antigen preparation of Toxoplasma gondii and its use in serological diagnosis. Clin Exp Immunol 1982, 49:239-246.

14. Semu SM, Peter TF, Mukwedeya D, Barbet AF, Jongejan F, Mahan SM: Antibody responses to MAP $1 B$ and other Cowdria ruminantium antigens are down regulated in cattle challenged with tick-transmitted heartwater. Clin Diagn Lab Immunol 2001, 8:388-396.

15. Torrey EF, Yolken RH: Toxoplasma oocysts as a public health problem. Trends Parasitol 2013, 29:380-384.

16. Scientific Opinion of the Panel on Biological Hazards on a Request from EFSA on Surveillance and monitoring of Toxoplasma in humans, food and animals. The EFSA Journal 2007, 583:1-64.

17. Frenkel JK, Ruiz A, Chinchilla M: Soil survival of Toxoplasma oocysts in Kansas and Costa Rica. Am J Trop Med Hyg 1975, 24:439-443.

18. Schoondermark-Vande Ven E, Melchers W, Galama J, Camps W, Eskes T, Meuwissen J: Congenital toxoplasmosis: an experimental study in rhesus monkeys for transmission and prenatal diagnosis. Exp Parasitol 1993, 77:200-211.

19. Holland GN, O'Connor GR, Diaz RF, Minasi P, Wara WM: Ocular toxoplasmosis in immunosuppressed nonhuman primates. Invest Ophthalmol Vis Sci 1988, 29:835-842.

20. Dubey JP, Ness SL, Kwok OC, Choudhary S, Mittel LD, Divers TJ: Seropositivity of Toxoplasma gondii in domestic donkeys (Equus asinus) and isolation of T. gondii from farm cats. Vet Parasitol 2014, 199:18-23.

21. Alvarado-Esquivel C, Estrada-Malacon MA, Reyes-Hernandez SO, Perez-Ramirez JA, Trujillo-Lopez Jl, Villena I, Dubey JP: High prevalence of Toxoplasma gondii antibodies in domestic pigs in Oaxaca State, Mexico. J Parasitol 2012, 98:1248-1250.

22. Cedillo-Pelaez C, Rico-Torres CP, Salas-Garrido CG, Correa D: Acute toxoplasmosis in squirrel monkeys (Saimiri sciureus) in Mexico. Vet Parasitol 2011, 180:368-371

23. Alvarado-Esquivel C, Gayosso-Dominguez EA, Villena I, Dubey JP: Seroprevalence of Toxoplasma gondii infection in captive mammals in three zoos in Mexico City, Mexico. J Zoo Wildl Med 2013, 44:803-806.

24. Ekanayake DK, Rajapakse RP, Dubey JP, Dittus WP: Seroprevalence of Toxoplasma gondii in wild toque macaques (Macaca sinica) at Polonnaruwa, Sri Lanka. J Parasitol 2004, 90:870-871.

25. Li HL, Yan C, Li J, Ai L, Zhou DH, Yuan ZG, Lin RQ, Zhao GH, Zhu XQ: Seroprevalence of Toxoplasma gondii in bred cynomolgus monkeys (Macaca fascicularis) in China. J Parasitol 2010, 96:807-808.

26. Cook AJ, Gilbert RE, Buffolano W, Zufferey J, Petersen E, Jenum PA, Foulon W, Semprini AE, Dunn DT: Sources of toxoplasma infection in pregnant women: European multicentre case-control study. European Research Network on Congenital Toxoplasmosis. BMJ 2000, 321:142-147.

27. Dubey JP, Kotula AW, Sharar A, Andrews CD, Lindsay DS: Effect of high temperature on infectivity of Toxoplasma gondii tissue cysts in pork. J Parasitol 1990, 76:201-204.

doi:10.1186/s13071-014-0571-x

Cite this article as: Hamilton et al.: First report of Toxoplasma gondii seroprevalence in wild-caught Caribbean African green monkeys. Parasites \& Vectors 2014 7:571.

\section{Submit your next manuscript to BioMed Central and take full advantage of:}

- Convenient online submission

- Thorough peer review

- No space constraints or color figure charges

- Immediate publication on acceptance

- Inclusion in PubMed, CAS, Scopus and Google Scholar

- Research which is freely available for redistribution 